16 Garcia-Aymerich J, Lange P, Benet $M$, et al. Regular physical activity reduces hospital admission and mortality in chronic obstructive pulmonary disease: a population based cohort study. Thorax 2006:61:772-8.

17 Evans WJ. Exercise, nutrition, and aging. Clin Geriatr Med 1995; 11:725-34.

18 Fiatarone MA, Marks EC, Ryan ND, et al. Highintensity strength training in nonagenarians. Effects on skeletal muscle. JAMA 1990;263:3029-34.

19 Gan WQ, Man SF, Senthilselvan A, et al. Association between chronic obstructive pulmonary disease and systemic inflammation: a systematic review and a meta-analysis. Thorax 2004;59:574-80.

20 Eid AA, lonescu AA, Nixon LS, et al. Inflammatory response and body composition in chronic obstructive pulmonary disease. Am J Respir Crit Care Med 2001;164:1414-18.

21 Schols AM, Buurman WA, Staal van den Brekel AJ, et al. Evidence for a relation between metabolic derangements and increased levels of inflammatory mediators in a subgroup of patients with chronic obstructive pulmonary disease. Thorax 1996;51:819-24.

22 Creutzberg EC, Schols AM, Weling-Scheepers CA et al. Characterization of nonresponse to high caloric oral nutritional therapy in depleted patients with chronic obstructive pulmonary disease. Am J Respir Crit Care Med 2000;161(P 1):745-52

23 Steiner MC, Barton RL, Singh SJ, et al. The nutritional enhancement of exercise performance in chronic obstructive pulmonary disease. A randomised controlled trial. Thorax 2003;58:745-51.

24 Dorrens J, Rennie MJ. Effects of ageing and human whole body and muscle protein turnover. Scand J Med Sci Sports 2003;13:26-33.

25 Reeves ND, Narici MV, Maganaris CN. Myotendinous plasticity to ageing and resistance exercise in humans. Exp Physiol 2006;91:483-98.

26 Cuthbertson D, Smith K, Babraj J, et al. Anabolic signaling deficits underlie amino acid resistance of wasting, aging muscle. FASEB J 2005; 19:422-4.

27 Hoffman EP, Nader GA. Balancing muscle hypertrophy and atrophy. Nat Med 2004; 10:584-5.

28 Pitta F, Troosters T, Probst VS, et al. Physical activity and hospitalization for exacerbation of COPD. Chest 2006;129:536-44.

29 Spruit MA, Gosselink R, Troosters T, et al. Muscle force during an acute exacerbation in hospitalised patients with COPD and its relationship with CXCL8 and IGF-I. Thorax 2003:58:752-6.

30 Man WD, Polkey MI, Donaldson N, et al. Community pulmonary rehabilitation after hospitalisation for acute exacerbations of chronic obstructive pulmonary disease: randomised controlled study. BMJ 2004:329:1209.

31 Murphy N, Bell C, Costello RW. Extending a home from hospital care programme for COPD exacerbations to include pulmonary rehabilitation. Respir Med 2005;99:1297-302.

32 Connors AF Jr, Dawson NV, Thomas C, et al. Outcomes following acute exacerbation of severe chronic obstructive lung disease. The SUPPORT investigators (Study to Understand Prognoses and Preferences for Outcomes and Risks of Treatments). Am J Respir Crit Care Med 1996;154(Pt 1):959-67.

33 Nici L, Donner C, Wouters E, et al. American Thoracic Society/European Respiratory Society statement on pulmonary rehabilitation. Am J Respir Crit Care Med 2006;173:1390-413.

34 Casaburi R, Patessio A, loli F, et al. Reductions in exercise lactic acidosis and ventilation as a result of exercise training in patients with obstructive lung disease. Am Rev Respir Dis 1991;143:9-18.

35 Maltais F, LeBlanc P, Simard C, et al. Skeletal muscle adaptation to endurance training in patients with chronic obstructive pulmonary disease. Am J Resp Crit Care Med 1996;154(Pt 1):442-7.

36 Cote CG, Celli BR. Pulmonary rehabilitation and the BODE index in COPD. Eur Respir J 2005; $26: 630-6$.

37 Schols AM, Soeters PB, Mostert R, et al. Physiologic effects of nutritional support and anabolic steroids in patients with chronic obstructive pulmonary disease. A placebo-controlled randomized trial. Am J Resp Crit Care Med 1995; 152(Pt 1): 1268-74.

38 Casaburi R, Bhasin S, Cosentino L, et al. Effects of testosterone and resistance training in men with chronic obstructive pulmonary disease. Am J Respir Crit Care Med 2004; 170:870-8

39 Ferreira I, Brooks D, Lacasse Y, et al. Nutritional intervention in COPD: a systematic overview. Chest $2001 ; 119: 353-63$

\title{
Chronic obstructive pulmonary disease exacerbation and risk of pulmonary embolism
}

\section{J A Wedzicha, J R Hurst}

\section{Pulmonary embolism is not a common feature in patients with chronic obstructive pulmonary disease with uncomplicated exacerbations}

E xacerbations of chronic obstructive pulmonary disease (COPD) are episodes of acute deterioration in respiratory symptoms ${ }^{1}$ that are accompanied by physiological changes ${ }^{2}$ and associated with increases in airway and systemic inflammation. ${ }^{3}$ These episodes are responsible for considerable morbidity and mortality, especially in patients with more severe COPD. ${ }^{5}$ There is consequently much interest in understanding the underlying pathophysiology of exacerbations and determining their triggers, so that appropriate interventions can be designed to prevent these events, reduce their severity and thus improve health status.

We now recognise that respiratory infections are important triggers of exacerbation. Respiratory viral infections, especially with human rhinovirus (the cause of the common cold), influenza and respiratory syncytial virus may be isolated from up to $60 \%$ of exacerbations. ${ }^{6}$ Exacerbations where a virus is isolated have increased airway and systemic inflammatory changes. ${ }^{3} 8$ The role of bacteria at exacerbation has been more difficult to determine as airway bacteria are also found in stable patients with COPD, especially those with more severe COPD. However, we now know that bacterial strain change may play a part in triggering exacerbation. ${ }^{9}$ Airway bacteria may be present in up to $70 \%$ of COPD exacerbations, and their isolation is accompanied by increased airway inflammatory changes. ${ }^{10}$ Viruses and bacteria may also be co-isolated from the same exacerbation, and recent studies have suggested that the presence of both pathogens may have a synergistic effect on the degree of airway inflammation, especially when exacerbations are severe. ${ }^{8-10-12}$ Thus, airway infection can be implicated as a trigger in most COPD exacerbations, even taking into account difficulties in sampling these patients that can lead to underestimating the significance of airway infection.

There is also interest in other causes of COPD exacerbation. Air pollution has been associated with an increase in hospital admissions in patients with COPD, although these effects are relatively small. ${ }^{13}$ As COPD exacerbations are closely linked to respiratory infections, the hypothesis has been put forward that pollutants can increase susceptibility to viral infection. One study has suggested that with higher personal nitrogen dioxide exposure, there is a greater risk of an asthmatic exacerbation after respiratory infection. ${ }^{14}$ Similar mechanisms might be operating in patients with COPD and further studies investigating the associations between pollution and infection are required.

Exacerbations therefore result from further insult to the COPD airway, but a number of conditions may mimic exacerbation by causing worsening dyspnoea in patients with underlying COPD. One such condition is pulmonary embolism, a disorder of the vasculature rather than the airway. Although pulmonary embolism is not thought to predispose to exacerbation, there have been a number of reports suggesting that the prevalence of deep venous thrombosis and pulmonary 
embolism is increased in patients with COPD exacerbation (although earlier results were based on small studies in selected hospitalised patients ${ }^{15}{ }^{16}$ ). The hypothesis that COPD exacerbations may trigger pulmonary embolic events is plausible as acute infections are known to predispose to deep venous thrombosis and pulmonary embolism. ${ }^{17}$ Furthermore, patients with COPD are often elderly, may be immobile, and often have systemic inflammation and co-morbid conditions, all of which increase susceptibility to venous thromboembolism. There may also be diagnostic difficulties as both COPD exacerbations and pulmonary embolism may present solely with dyspnoea. A recent study by Tillie-Leblond et al ${ }^{18}$ reported a $25 \%$ prevalence of pulmonary embolism in patients with COPD hospitalised for severe exacerbations "of unknown origin". An unusual feature of this study was that the authors excluded all patients in whom a potential infective cause for exacerbation was identified: they excluded exacerbations associated with increased sputum volume or sputum purulence, or a history of colds and sore throats, which indicates viral infection. Thus, the patients recruited into this study were highly selected and not representative of most exacerbations presenting to primary or secondary care that are usually accompanied by some manifestation of airway infection. In this study, exacerbations were defined as an acute deterioration requiring hospitalisation, and it is not clear whether patients just presented with worsening symptoms of dyspnoea or may have developed other conditions such as heart failure that could increase the risk of pulmonary embolism.

In this issue of Thorax, Rutschmann et $a l^{19}$ describe a further interesting study investigating the prevalence of pulmonary embolism at COPD exacerbations. (see page 121) In contrast with the study by TillieLeblond, Rutschmann et al included consecutive patients admitted to emergency departments with COPD exacerbations and investigated all the patients for pulmonary embolism, regardless of clinical suspicion. Investigation involved a standardised algorithm based on D-dimer testing, lower limb venous ultrasonography and multidetector helical computerised tomography scan. The data showed that the prevalence of pulmonary embolism was $6.2 \%$ in patients with COPD with clinical suspicion of pulmonary embolism, and only $1.3 \%$ where there was no clinical suspicion of pulmonary embolism. The authors conclude that as the prevalence of pulmonary embolism is so low, systematic investigation in patients presenting with COPD exacerbations is not required.
So is this the final conclusion: that pulmonary embolism is not an issue in patients with COPD with uncomplicated exacerbations? The results of this study are consistent with the clinical observation that most moderate to severe exacerbations in patients with COPD last between 7 and 10 days, respond well to therapy, and recover to their baseline symptoms and lung function. Some patients with COPD are prone to frequent exacerbations; they may be susceptible to respiratory viral infection $s^{20}$ and are these patients more prone to develop PE? Perhaps, however, these patients are more prone to developing pulmonary embolism. Furthermore, we also recognise that in some patients, an index COPD exacerbation may be followed closely in time by another "recurrent" exacerbation, ${ }^{21}$ and this is consistent with the observation that patients admitted to hospital with exacerbations are subsequently at an increased risk of readmission. ${ }^{22}$ It is thus possible that in addition to airway infection, venous thromboembolism may play a part in exacerbation recurrence.

Airway infection is the most important trigger of COPD exacerbations, and strategies to reduce airway viruses and bacteria should be the most effective interventions to prevent or reduce these events. The paper by Rutschmann et al suggests that pulmonary embolism is not a common feature of the uncomplicated exacerbation at presentation. However, some exacerbations can have prolonged recovery periods, complicated by respiratory failure and co-morbidity, when the risk of pulmonary embolism may become greater. It is these exacerbations that have particular health economic implications and require our future efforts.

Thorax 2007;62:103-104.

doi: $10.1136 /$ thx.2006.073098

\section{Authors' affiliations}

J A Wedzicha, J R Hurst, Academic Unit of Respiratory Medicine, Royal Free and University College Medical School, University College London, Hampstead, UK

Correspondence to: Professor J A Wedzicha, Academic Unit of Respiratory Medicine, Royal Free and University College Medical School, University College London, Rowland Hill Street, Hampstead NW3 2PF, UK;

j.a.wedzicha@medsch.ucl.ac.uk

Competing interests: None declared.

\section{REFERENCES}

1 Seemungal TAR, Donaldson GC, Bhowmik A, et al. Time course and recovery of exacerbations in patients with chronic obstructive pulmonary disease. Am J Respir Crit Care Med 2000;161:1608-13.

2 O'Donnell DE, Parker CM. COPD exacerbations. 3 : Pathophysiology, Thorax 2006;61:354-61.

3 Wedzicha JA, Seemungal TAR, MacCallum PK, et al. Acute exacerbations of chronic obstructive pulmonary disease are accompanied by elevations of plasma fibrinogen and serum IL-6 levels. Thromb Haemost 2000;84:210-15.

4 Hurst JR, Perera WR, Wilkinson TMA, et al. Systemic, upper and lower airway inflammation at exacerbation of COPD. Am J Respir Crit Care Med 2006;173:71-8.

5 Donaldson GC, Wedzicha JA. COPD exacerbations. 1: Epidemiology. Thorax 2006;61:164-8.

6 Seemungal TAR, Harper-Owen R, Bhowmik A, et al. Respiratory viruses, symptoms and inflammatory markers in acute exacerbations and stable chronic obstructive pulmonary disease. Am J Respir Crit Care Med 2001; 164:1618-23.

7 Falsey AR, Hennessey PAN, Formica AM, et al. Respiratory syncytial virus infection in elderly and high-risk adults. N Engl J Med 2005;352:1749-59.

8 Bhowmik A, Seemungal TAR, Sapsford R, et al. Relation of sputum inflammatory markers to symptoms and physiological changes at COPD. Thorax 2000;55:114-20.

9 Sethi S, Evans N, Brydon JB, et al. New strains of bacteria and exacerbations of chronic obstructive pulmonary disease. N Engl J Med 2002;347:465-71.

10 Sapey E, Stockley RA. COPD exacerbations. 2: Aetiology. Thorax 2006;61:250-8.

11 Wilkinson TMA, Hurst JR, Perera WR, et al. Interactions between lower airway bacterial and rhinoviral infection at exacerbations of chronic obstructive pulmonary disease. Chest 2006; 129:317-24.

12 Papi A, Bellettato CM, Braccioni F, et al. Infections and airway inflammation in chronic obstructive pulmonary disease severe exacerbations. Am J Respir Crit Care Med 2006;173:1 1 14-21.

13 Anderson HR, Spix C, Medicna S, et al. Air pollution and daily admissions for chronic obstructive pulmonary disease in 6 European cities: results from the APHEA project. Eur Respir $J$ 1998;11:992-3.

14 Linaker CH, Coggon D, Holgate ST, et al. Personal exposure to nitrogen dioxide and risk of airflow obstruction in asthmatic children with upper respiratory infection. Thorax 2000;55:930-33.

15 Winter JH, Buckier PW, Bautista AP, et al. Frequency of venous thrombosis in patients with exacerbation of chronic obstructive lung disease. Thorax 1983;38:605-8.

16 Erelel M, Cuhadarogiu C, Ece T, et al. The frequency of deep venous thrombosis and pulmonary embolus in acute exacerbation of chronic obstructive pulmonary disease. Respir Med 2002;96:515-18.

17 Smeeth L, Cook, C, Thomas S, et al. Risk of deep vein thrombosis and pulmonary embolism after acute infection in a community setting. Lancet 2006;367:1075-9.

18 Tillie-Leblond I, Marquette C-H, Perez T, et al. Pulmonary embolism in patients with unexplained exacerbation of chronic obstructive pulmonary disease: prevalence and risk factors. Ann Intern Med 2006;144:390-6.

19 Rutschmann OT, Cornuz J, Poletti P-A, et al. Should pulmonary embolism be suspected in exacerbation of chronic obstructive pulmonary disease? Thorax 2007;62:121-5.

20 Hurst JR, Donaldson GC, Wilkinson TMA, et al. Epidemiological relationships between the common cold and exacerbation frequency in COPD. Eur Respir J 2005;26:846-52

21 Perera WR, Hurst JR, Wilkinson TMA, et al. Inflammatory changes, recovery and recurrence at COPD exacerbation. Eur Respir J 2002;19:217.

22 Roberts CM, Lowe D, Bucknell CE, et al. Clinical audit indicators of outcome following admission to hospital with acute exacerbation of chronic obstructive pulmonary disease. Thorax 2002;57:137-41. 


\section{PostScript}

\section{LETTER}

\section{Pulmonary hypertension in Hodgkin's disease}

We wish to share our experience in an unusual case presentation of pulmonary hypertension. A 48-year-old Caucasian female with a history of hypothyroidism and smoking presented with progressive dyspnoea on exertion for 3 years, markedly worse during the past 6 months. She also had arthralgias, Raynaud's phenomena, night sweats and a 25-pound weight loss over 6 months. Chest computed tomography scan showed diffuse mediastinal lymphadenopathy. Lymph node biopsy showed non-necrotising epithelioid granulomas compatible with sarcoidosis Symptoms worsened despite treatment with prednisone.

Pulmonary function tests showed mild restrictive disease, reduced diffusion capacity and desaturation during a 6-min walk. Echocardiogram showed a severely dilated and hypokinetic right ventricle. Right heart catheterisation showed pulmonary artery pressure $79 / 38 \mathrm{~mm} \mathrm{Hg}$ (mean $46 \mathrm{~mm} \mathrm{Hg}$ ), cardiac output $6.7 \mathrm{l} / \mathrm{min}$ and cardiac index $3.7 \mathrm{l} / \mathrm{min} /$ $\mathrm{m}^{2}$. There was no significant response to inhaled nitric oxide at $20 \mathrm{ppm}$.

A retrospective review of her pathology showed a dominant reaction pattern consistent with sarcoidosis, small foci of paracortical infiltration by large mononuclear and binucleated haematopoietic elements, and a concomitant background of tissue eosinophilia. Immunohistostaining was consistent with mixed cellularity Hodgkin's lymphoma (fig l).

She was initiated on epoprostenol by continuous infusion. Owing to her pulmonary and cardiac disease, she received six cycles of chlorambucil, vinblastine, procarbazine and prednisone. She achieved a complete response and remains in remission 20 months after chemotherapy. She continues on epoprostenol therapy with improved exercise tolerance. Repeat right heart catheterisation showed pulmonary artery pressure 48/21 (mean $30 \mathrm{~mm} \mathrm{Hg})$, cardiac output $7.8 \mathrm{l} / \mathrm{min}$ and cardiac index $4.6 \mathrm{l} / \mathrm{min} / \mathrm{m}^{2}$. Attempts to wean epoprostenol were unsuccessful.

Sarcoid-like reactions are defined as areas of non-caseating granulomas seen on biopsy in patients without symptoms of systemic sarcoidosis. Radiographically, patients with intrathoracic sarcoid-like reactions may present with hilar or mediastinal adenopathy, ground-glass infiltrates or a perivascular nodularity mimicking sarcoidosis. Among the various conditions associated with a sarcoid-like diathesis are infections, hypersensitivity reactions, and solid or haematological malignancies.

In malignancy, this pathology can be seen at the primary tumour site, particularly in $\mathrm{T}$ cell

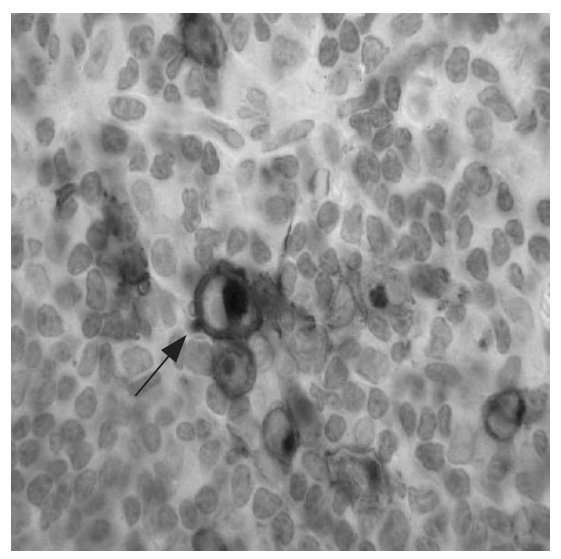

Figure 1 The neoplastic cell populace shows characteristic CD30 positivity (arrow) manifesting a sharp, cytoplasmic, membrane-like and perinuclear staining pattern (avidin biotin dibenzidine $\times 1000$ )

lymphoma and Hodgkin's disease, in lymph nodes draining the region, or in distant organs such as the spleen, liver or bone marrow. Up to $4.4 \%$ of patients with carcinoma, $7.3 \%$ of patients with non-Hodgkin's lymphoma and $13.8 \%$ of patients with Hodgkin's disease will feature sarcoid-like reactions. ${ }^{2}$

Pulmonary arterial hypertension (PAH) develops in up to $28 \%$ of patients with sarcoidosis. ${ }^{3}$ The aetiology of PAH in sarcoidosis is generally presumed to be secondary to parenchymal fibrosis and hypoxaemia. However, PAH may develop in patients without extensive parenchymal destruction secondary to perivascular or intravascular granulomatous inflammation, granulomatous angiitis, extrinsic compression of the main or peripheral pulmonary arteries by mediastinal lymph nodes or fibrosis with resultant pulmonary stenosis. $^{5}$

The response of PAH secondary to sarcoidosis in the treatment for sarcoidosis is uncertain in a case series, the haemodynamic response to steroid therapy was found to be lagging behind the radiographic and pulmonary function test improvement, and was not universally seen. In a small study, patients with severe $\mathrm{PAH}$ secondary to sarcoidosis were found responsive to vasodilator therapy. ${ }^{3} \mathrm{PAH}$ in association with sarcoid-like reactions is not described and management is unproven.

No cases of PAH secondary to a sarcoid-like reaction or Hodgkin's disease have been reported previously. This case underscores the association of lymphoma and sarcoid-like reactions, and the possibility that $\mathrm{PAH}$ in these patients may be underappreciated. This case also emphasises the importance of a systematic evaluation for lymphoproliferative disease in patients with lymphadenopathy presumed to be sarcoidosis.

Matthew Exline, Cynthia Magro, Thomas Lin Namita Sood

Department of Medicine, Department of Pathology, The Ohio State University, Columbus, OH 43210, USA

Correspondence to: N Sood, Department of Medicine, Department of Pathology, The Ohio State University, Columbus, OH, USA; namita.sood@osumc.edu doi: $10.1136 /$ thx.2006.070029

Competing interests: None declared.

\section{References}

1 Hunsaker AR, Munden RF, Pugatch RD, et al. Sarcoid-like reaction in patients with malignancy. Radiology 1996;200:255.

2 Brincker H. Sarcoid reactions and sarcoidosis in Hodgkin's disease and other malignant lymphomata. Br J Cancer 1972;26:120.

3 Preston IR, Klinger JR, Landzberg MJ, et al. Vasoresponsiveness of sarcoidosis-associated pulmonary hypertension. Chest 2001;120:866.

4 Salazar A, Mana J, Sala J, et al. Combined portal and pulmonary hypertension in sarcoidosis. Respiration 1994:61:117.

5 Nunes H, Humbert M, Capron F, et al. Pulmonary hypertension associated with sarcoidosis: mechanisms, haemodynamics and prognosis. Thorax 2006;61:68

6 Gluskowski J, Hawrylkiewicz I, Zych D, et al. Effects of corticosteroid treatment on pulmonary haemodynamics in patients with sarcoidosis. Eur Respir J 1990:3:403.

\section{CORRECTIONS}

doi: 10.1136/thx.2005.045591corr l

In the paper by Rudd et al (Thorax 2007;62:6266) from the January issue, the abbreviation TLCO was incorrectly expanded to "reduced carbon monoxide transfer factor", when in fact it should have been "carbon monoxide transfer factor". This occurs in the penultimate sentence of the results section of the abstract, the abbreviations list and the legend of figure 1 .

doi: 10.1136/thx.2006.73098corr 1

Incorrect reference details were inserted into reference 21 of the editorial by Wedzicha and Hurst, published in the February issue (Thorax 2007;62:103-104). The reference should not be Eur Respir J 2002;19:217. The correct reference details are: Eur Respir J, published online before print November 15, 2006 as doi: 10.1183/ 09031936.00092506 